\title{
ENSINO MÉDIO ESTATAL: MENOS VERBAS PARA MAIS ALUNOS?
}

Nicholas Davies 1

Resumo O artigo traça um panorama de alguns desafios estruturais e conjunturais para o financiamento da educação estatal, em particular o ensino médio, mostrando que a tendência dos governos tem sido no sentido de gastar menos por aluno, apesar dos discursos oficiais de exaltação da qualidade do ensino. Entre os desafios estruturais, incluem-se o privatismo direto e indireto das políticas oficiais, o descumprimento da exigência de aplicação da verba vinculada à manutenção e desenvolvimento do ensino, a perda de recursos vinculados causada pela inflação e pelas medidas de política fiscal, e a pouca confiabilidade dos Tribunais de Contas. Entre os desafios conjunturais, analisamos o Fundo de Manutenção e Desenvolvimento do Ensino Fundamental e de Valorização do Magistério (Fundef) - que não traz recursos novos para o sistema educacional como um todo e deixa de fora o ensino médio -, a reduzida contribuição federal para o ensino médio e a fragilidade da proposta do PNE (Plano Nacional de Educação) e o uso "judicioso" do dinheiro público. Por fim, examinamos as perspectivas - pouco animadoras de financiamento da educação no governo Lula: a ênfase do governo no "ajuste fiscal", cuja conseqüência foi a diminuição, em termos reais, das verbas para a educação em 2003; e as virtudes e os limites do Fundeb (Fundo da Educação Básica). Palavras-chave financiamento da educação; ensino médio.
Abstract The article provides an overview of some structural and conjunctural challenges for the funding of State education, particularly secondary education (the 3 years of schooling offered after the 8-year period of compulsory education), showing that the trend of governments has been to spend less per pupil, despite the official discourses exhalting the quality of education. The structural challenges examined include direct and indirect privatism of government policies, the non-compliance of a constitucional requirement that a certain percentage of taxes be invested in education, the loss of funds linked to education caused by inflation and fiscal policies, and the little reliability of Audit Offices (official bodies in charge of auditing government accounts). Among the conjunctural challenges we have examined the Fundef (a fund set up by the federal government to finance compulsory education), which does not bring further funds for the educational system as a whole and leaves out the secondary education; the reduced federal contribution to the secondary education; and the fragility of the proposal contained in the 10-year National Education Plan and the "judicious" use of public money. Finally, we examine the perspectives of education funding in Lula's government, which are not apparently bright in view of the emphasis of his government on the "fiscal adjustment", the result of which was a reduction in real terms of the funds for education in 2003. We have also analysed the virtues and limits of the Fundeb (the Basic Education Fund).

Key words education funding; secondary edu- 


\section{Introdução}

Para uma compreensão do financiamento do ensino médio no Brasil, é preciso antes uma breve discussão sobre o caráter do Estado brasileiro e de suas políticas sociais mais recentes, entre elas as educacionais. O Estado brasileiro, como todo Estado capitalista, tem sua estrutura e ação orientadas para atender principalmente aos interesses gerais das classes dominantes e também aos específicos de suas várias frações. Não constitui um bloco monolítico e reflete, em maior ou menor grau, não só diferenças e divergências no seio das classes dominantes, como também, embora minoritariamente, os interesses e as ações das várias frações das classes trabalhadoras e/ou das entidades e dos partidos que alegam representá-las. Vale ressaltar que o Estado não apenas reflete direta e imediatamente essas contradições, como também atua sobre a sociedade por deter certa autonomia em relação às classes sociais. Essa autonomia é necessária para a legitimidade perante as classes dominadas e variável em função da organização e capacidade das várias classes e suas frações para fazerem valer seus interesses junto aos aparelhos estatais. Além destes traços gerais, o Estado brasileiro apresenta particularidades, definidas por sua história e inserção variável na divisão internacional do trabalho e do poder, representadas, por exemplo, pelo forte patrimonialismo dos ocupantes de cargos públicos, pelo autoritarismo exacerbado, pela impermeabilidade às demandas das classes populares e médias e pela subordinação aos centros hegemônicos do capitalismo (EUA, Japão, Europa Ocidental).

Se estrutural e historicamente o Estado brasileiro não tem demonstrado compromisso com os interesses mais amplos da maioria da população, sobretudo os dos trabalhadores e oprimidos de todo tipo, a conjuntura dos anos 90 aumentou este descaso. A crise de reprodução do capitalismo em escala mundial, com reflexos nas políticas denominadas de neoliberais, e o desmoronamento dos regimes ditos socialistas do Leste Europeu intensificaram, com a orientação e a direção de organismos como o Banco Mundial e o Fundo Monetário Internacional, a ofensiva mundial do capital no sentido de recuperar terreno perdido para os setores organizados de trabalhadores nas décadas anteriores (diminuindo ou anulando direitos sociais e trabalhistas) e conquistar novos espaços para sua reprodução (privatizando juridicamente setores ocupados pelo Estado).

No Brasil, em que os movimentos populares viveram um ascenso nos anos 80, esta ofensiva começa com a eleição presidencial de Fernando Collor, em 1990, e se amplia e consolida com o presidente Fernando Henrique Cardoso (FHC), cujas políticas propuseram a redução do papel do Estado na economia e em outros setores como educação, com base no diagnóstico de ineficiência e má gestão do Estado. Este teria o seu déficit sanado pela me- 
lhor gestão ou redução dos gastos estatais ou seu redirecionamento para setores supostamente mais carentes ou de retorno econômico mais seguro. Como não poderia deixar de ser, tal diagnóstico não se dispõe a identificar a origem desse déficit no controle do Estado pelo capital privado, que dele se serviu e se serve para financiar suas ações produtivas e especulativas.

Este diagnóstico e as políticas daí decorrentes estão presentes nas ações governamentais dos últimos anos. Antes de examinarmos algumas delas e suas implicações para o financiamento do ensino médio, consideramos fundamental abordar algumas questões gerais, estruturais, sobre o financiamento da educação estatal, cujo estudo ilumina as prioridades reais (e não apenas as discursivas, freqüentemente destinadas a ocultar as reais) dos governos.

\section{Desafios estruturais}

Uma primeira questão estrutural, anterior à ofensiva neoliberal dos anos 90 e ainda presente hoje, é o privatismo direto e indireto das políticas oficiais em vários setores, inclusive o educacional. As escolas privadas, ainda que com denominações diversas, como filantrópicas, comunitárias e confessionais, têm gozado de uma série de privilégios oficiais ao longo das últimas décadas. Um deles foi a isenção de todos os impostos desde a Constituição Federal (CF) de 1946, que continuou até a Constituição mais recente (Brasil, 1988), embora esta tenha introduzido a exigência de que tais escolas não tenham fins lucrativos, exigência que não é difícil de burlar, como mostra Velloso (1988a).

Outro privilégio foi a isenção da contribuição previdenciária patronal das filantrópicas, instituída por uma lei de 1959 (Lei 3.577, de 4/7/59), que representa uma economia de cerca de $20 \%$ da sua folha de pagamento. Embora a Lei federal 9.732, de 1998, tenha criado exigências mais rigorosas para o gozo deste privilégio, as instituições filantrópicas conseguiram, mediante Ação Direta de Inconstitucionalidade junto ao Supremo Tribunal Federal, suspender a vigência dos dispositivos com tais exigências. Além destas isenções, as escolas privadas foram e ainda são beneficiadas com vários mecanismos diretos - subvenções, empréstimos a fundo perdido ou a juros subsidiados e outros, como o salário-educação, criado em 1964, e o crédito educativo, instituído em 1975 e substituído em 1999 pelo Financiamento do Estudante do Ensino Superior (FIES) (Velloso, 1988a; Davies, 2002). Sem estes privilégios, o setor privado (sobretudo no ensino superior) não teria crescido tanto nas últimas décadas, enfraquecendo, em termos relativos

pelo menos, o setor estatal, que, embora tenha se expandido quantitativamente, vem sofrendo uma grande deterioração. 
Outra questão fundamental, de natureza estrutural, que relativiza bastante qualquer aumento contábil de recursos para a educação, é o descumprimento da exigência constitucional de aplicação do percentual mínimo de impostos em Manutenção e Desenvolvimento do Ensino (MDE), exigência que sofreu vicissitudes desde sua inclusão pela primeira vez na Constituição Federal de 1934, tendo sido suprimida na Constituição do Estado Novo, em 1937, restaurada na CF de 1946, eliminada novamente na de 1967 e, finalmente, restabelecida em 1983, com a Emenda Calmon. Segundo Maria Malta Campos (1985, p. 84), com base em trabalho de Carlos Correa Mascaro, os recursos da educação da prefeitura de São Paulo, no período anterior e posterior a 1945, não teriam sido aplicados corretamente. Em âmbito federal, Jacques Velloso (1988b, p. 360) registra que a Emenda Calmon foi flagrantemente violada desde sua aprovação. Mais recentemente, o deputado estadual Callegari $(1997,1999)$ denunciou que o governo estadual de São Paulo deixou de aplicar mais de R \$ 5,2 bilhões devidos legalmente em MDE no período de 1995 a 1998, montante que seria acrescido de $\mathrm{R} \$ 1,5$ bilhão com base na previsão orçamentária para 1999, totalizando, assim, $\mathrm{R} \$ 6,7$ bilhões em cinco anos.

No estado do Rio de Janeiro, os estudos que realizamos sobre os gastos em MDE, tanto do governo estadual quanto de 15 prefeituras, também constataram esse descumprimento. Enquanto o governo estadual deixou de prever mais de R 600 milhões em MDE em 1997 (Davies, 2000), a prefeitura do Rio deixou de aplicar mais de R 1 bilhão devido legalmente em MDE em 1998 e 1999 (Davies, 2001a). Reconhecendo "a existência de uma enorme diferença entre o que é legalmente destinado à educação em termos de recursos públicos e o que é efetivamente gasto", o próprio Ministério da Educação e Cultura indica, em seu Plano Nacional de Educação encaminhado como projeto de lei em 1998, como "primeira prioridade, em termos de financiamento, para os próximos cinco anos, (...) garantir que os recursos legalmente destinados à educação sejam efetivamente empregados com esta finalidade" (MEC, 1998, p. 78).

Além disso, durante muitos anos a vinculação foi minada por uma inflação astronômica (que, em certos períodos, chegou a alcançar 30\% a 40\% ao mês!), uma sonegação fiscal gigantesca, facilitada pela corrupção generalizada dos órgãos fiscalizadores, e por manobras fiscais ou medidas de políticas fiscal e econômica, como o Fundo de Estabilização Fiscal (FEF), a Lei Kandir (Lei Complementar 87/96) e a classificação irregular de imposto como contribuição.

Em época de inflação alta, os governos se baseavam apenas nos valores nominais na prestação de contas da verba aplicada em educação, não os corrigindo monetariamente, ao contrário do que faziam com os impostos devidos, estes, sim, corrigidos por um índice de atualização fiscal. Isso represen- 
tou uma perda astronômica para a educação, que continua a acontecer hoje, mesmo com a inflação relativamente baixa. Estudiosos do assunto já mostraram tais prejuízos.

Outro artifício tem sido classificar como contribuição o que é imposto. Como só os impostos são vinculados à MDE, esta manobra tem resultado em perdas enormes para a educação. Um estudo da evolução da receita federal desde a CF de 1988 até hoje revelaria que a participação percentual dos impostos na receita global vem caindo em favor de receitas que não sejam impostos, como as contribuições - o exemplo mais recente é a Contribuição Provisória (Permanente?) sobre Movimentação Financeira. Cândido Gomes (1994, p. 11) oferece informações que confirmam essa suspeita, ao mostrar que as despesas do governo federal na função Educação e Cultura (conceito mais amplo do que MDE) caíram de 8,2\%, em 1988, para 2,1\%, em 1993, em relação às despesas totais. Não dispomos de dados mais recentes, mas é provável que este percentual tenha caído ainda mais, pois o Fundo Social de Emergência, criado por Emenda Constitucional em 1994 e posteriormente transformado em Fundo de Estabilização Fiscal (FEF), subtraiu bilhões da educação pela desvinculação de $20 \%$ da receita de alguns impostos. A conseqüência do FEF é que o governo federal só foi obrigado a aplicar $14,4 \%$ da receita de impostos em $\mathrm{MDE}$, pois $20 \%$ dos $18 \%$ (= $3,6 \%$ ) foram retidos automaticamente no FEF, para uso livre, desvinculado, pelo governo federal.

Também a educação de estados, Distrito Federal e municípios foi prejudicada pelo FEF, em conseqüência da diminuição da receita do FPE (Fundo de Participação dos Estados) e do FPM (Fundo de Participação dos Municípios), ambos formados por dois impostos federais (Imposto de Renda e Imposto sobre Produtos Industrializados) e destinados aos governos subnacionais (estados, Distrito Federal e municípios). O FEF também afetou negativamente a educação, ao desvincular $20 \%$ do salário-educação, correspondente a centenas de milhões de reais por ano na década de 1990. Segundo Ramiro Wahrhafting (1999, p. 208), presidente do Conselho Nacional de Secretários Estaduais de Educação (Consed) e secretário estadual de educação do Paraná, "como conseqüência da prorrogação do FEF, o prejuízo estimado para 1998 (...) é de cerca de R\$ 600 milhões, dos quais dois terços incidentes sobre o valor a ser rateado pelos Estados - o que representa volume de recursos maior do que o montante que o governo federal deverá aplicar na complementação do Fundef".

Embora o FEF tenha sido extinto em dezembro de 1999, as perdas em âmbito federal continuaram de 2000 a 2003, pois, em março de 2000, foi aprovada nova Emenda Constitucional, de no 27, (a DRU, ou Desvinculação de Receita da União), que reproduziu parte da Emenda do FEF e desvinculou $20 \%$ dos impostos federais, o que significa concretamente que o gover- 
no federal continuou sendo legalmente obrigado a aplicar somente 14,4\% da receita de impostos em MDE, e não $18 \%$. Este prejuízo deve continuar pelo menos até 2007, em conseqüência da prorrogação da DRU, por iniciativa do atual governo federal.

Outro dano ao financiamento da educação estatal é a Lei Kandir, que, ao desonerar o Imposto sobre a Circulação de Mercadorias e Serviços (ICMS) das exportações de alguns produtos, a pretexto de aumentar a competitividade das exportações brasileiras, reduziu a receita de impostos vinculados à MDE. Segundo notícia do jornal O Globo, em 21 de agosto de 1997, a propósito de reunião de Secretários Estaduais de Fazenda, as perdas em 1997 seriam de R\$ 3,6 bilhões. Considerando-se que no mínimo $25 \%$ deste montante se destinaria à MDE, a educação de estados, Distrito Federal e municípios terá perdido R \$ 900 milhões (ou até mais, tendo em vista que alguns estados e municípios são obrigados a aplicar mais de $25 \%$ em educação).

Uma terceira questão de ordem estrutural seria a pouca confiabilidade e/ou competência dos Tribunais de Contas. Antes de comentar a atuação deles, cabe lembrar que são órgãos auxiliares do Poder Legislativo, dirigidos por conselheiros nomeados segundo critérios políticos, a partir de acordos entre o Executivo e os "representantes" do povo (deputados e vereadores). Isso significa que as contas dos governos tendem a ser avaliadas, principalmente, segundo critérios de "afinidade" entre os TCs e os governos, não necessariamente de acordo com a lei ou normas técnicas, já que estas, muitas vezes (talvez quase sempre), são aplicadas seletivamente. Uma frase famosa no Brasil resume bem a atitude dos TCs e também do Poder dito Público como um todo: "para os amigos, tudo; para os inimigos, a lei".

Além dessa pouca confiabilidade, os TCs adotam as interpretações mais variadas sobre o que consideram receitas e despesas vinculadas à MDE, muitas vezes divergentes do espírito e mesmo da letra das disposições legais. Vale ressaltar que tais interpretações são mais importantes do que as disposições constitucionais ou a nova Lei de Diretrizes e Bases da Educação Nacional (Lei 9.394/96), uma vez que os governos estaduais e municipais procuram seguir (quando o fazem, é claro) tais interpretações, materializadas em instruções normativas ou resoluções dos TCs, e não as disposições constitucionais ou da LDB.

Em estudo sobre os procedimentos adotados pelos TCs de quase todos os estados brasileiros (são 26 tribunais estaduais, um do Distrito Federal e 6 municipais), constatamos muitas diferenças e divergências entre eles, que têm resultado em diminuição dos recursos vinculados à MDE (Davies, 2001 b). Por exemplo, os TCs de Minas e Rio de Janeiro não incluem os impostos atrasados (lançados na rubrica da dívida ativa tributária nos orçamentos e balanços) na base de cálculo do percentual mínimo. Outra diver- 
gência significativa está no cálculo das receitas que devem ser computadas como acréscimos ao mínimo, como as oriundas de convênios, salário-educação e ganhos com o Fundef. Enquanto alguns TCs verificam se tais receitas são acrescidas ao montante correspondente ao percentual mínimo, calculado com base apenas na receita de impostos, outros aceitam ou aceitaram incorretamente a sua inclusão na base de cálculo, como os do município (TCM) e do estado (TCE) do Rio de Janeiro.

Também constatamos divergência nas interpretações dos TCs sobre o que consideram despesas legais em MDE. Segundo Callegari (1997, 1999), o TC do estado de São Paulo tem aceito a inclusão do pagamento dos inativos da educação, correspondente a cerca de R 1 1,957 bilhão em 1998, nas contas do governo, o mesmo fazendo o de Minas Gerais. No município do Rio de Janeiro, os gastos de R $\$ 316$ milhões com os aposentados em 1999, cerca de $40 \%$ do total despendido com o pessoal da educação, têm sido computados pela prefeitura como MDE e aceitos pelo TCM. Entretanto, alguns TCs (Pará, Maranhão e Paraíba) adotam uma interpretação contrária, a nosso ver mais correta, uma vez que os aposentados não mais contribuem para manter e desenvolver o ensino, finalidade a que se destina o percentual mínimo. Os gastos com os inativos, que vêm crescendo de modo acelerado e representando, em alguns estados, de 30 a $40 \%$ dos gastos com todo o pessoal da educação, significam concretamente a diminuição de recursos legais para as demais despesas da educação, dificultando, assim, a manutenção e, sobretudo, a expansão da educação estatal, pelo menos com base no percentual mínimo.

As irregularidades na classificação das despesas em MDE têm sido tantas que dois especialistas no assunto (Velloso, 1988a, e Melchior, 1988) dedicaram longas páginas a uma discussão sobre o assunto, e o capítulo dos recursos financeiros na LDB de 1996 reservou dois extensos artigos (70 e 71) para definir o que pode ser considerado como despesas em MDE. Porém, apesar do avanço legal, persistiram alguns problemas, pois a despesa com os inativos não está explicitada em nenhum dos artigos, permitindo que autoridades e TCs adotassem as interpretações que mais lhes conviessem. O problema da inclusão ilegal de despesas em MDE é bem ilustrado em documento do TC do Rio Grande do Sul que relaciona 37 tipos de despesas ilegais que os governos gaúchos (e isso provavelmente valeria também para outros governos estaduais e municipais) consideravam de MDE. Vejam-se alguns exemplos: construção de ginásio ou centro esportivo comunitário, pavimentação de ruas de acesso ou fronteiriças a prédios ou instalações escolares, construção de abrigos em paradas de ônibus nas zonas rural e urbana, construção de poços tubulares profundos (artesianos), realização de eventos (como festivais musicais e de teatro, shows e rodeios) (Rio Grande do Sul, 1998, p. 58-59). 
Até mesmo a pormenorização das despesas admissíveis como MDE no documento legal não resolveria um problema aparentemente insolúvel nas contas da educação, que é a maquiagem contábil. Por exemplo, um governo pode lançar na documentação contábil uma despesa como se fosse da educação, mas que concretamente é de outro setor. Ou, então, na sua prestação anual de contas, declarar como gastos o montante empenhado em MDE, porém, no exercício seguinte, cancelar uma parte ou a totalidade destes empenhos. O governo estadual do Rio de Janeiro fez isso em 1996 e o TC não demonstrou atenção para essa manobra contábil. Neste caso, a diferença entre o montante empenhado e o pago foi astronômica. Até 31 de dezembro de 1996, o governo estadual declarou ter pago cerca de R $\$ 650$ milhões à Secretaria de Educação, porém, na sua prestação de contas, alegou ter aplicado o total empenhado de R\$1,4 bilhão nesse ano. Em 1997, uma proporção significativa da diferença de $\mathrm{R} \$ 750$ milhões ( $\mathrm{R} \$ 1,4$ bilhão menos $\mathrm{R} \$ 650$ milhões) foi simplesmente cancelada e, portanto, não paga, mas as contas do governo estadual foram aprovadas pelo TC na suposição de que o montante de R\$ 1,4 bilhão foi efetivamente gasto em MDE. Embora estudiosos do assunto estejam atentos para a questão - um exemplo é o Parecer no 26, de dezembro de 1997, do Conselho Nacional de Educação — a maioria dos TCs não demonstra conhecê-lo e não parece fiscalizar essa manobra contábil. Tal parecer estabelece que só deveriam ser contabilizadas as despesas pagas ou liquidadas no exercício, excluindo, assim, as que tivessem sido apenas empenhadas e que, portanto, poderiam vir a ser canceladas no exercício seguinte.

Mesmo quando os TCs adotam procedimentos corretos de verificação das receitas e despesas vinculadas à MDE, os seus pareceres, na prática, não têm nenhuma força de lei, pois, segundo o Art. 31 da Constituição Federal, no caso das contas municipais, podem ser derrubados por dois terços dos vereadores. Ora, como a relação entre os governantes e os chamados representantes do povo é de "toma lá, dá cá", ou, em outras palavras, troca de favores, tais representantes tendem a aprovar as contas dos governantes, mesmo quando elas foram rejeitadas pelos TCs.

Embora a CF preveja a intervenção nos estados e municípios que não cumpram a lei, o ex-senador João Calmon, em depoimento prestado à Comissão Parlamentar de Inquérito instalada em 1988 para averiguar a aplicação do percentual mínimo, informava que

“A violação na área dos governos estaduais é realmente generalizada. Em relação à violação na área dos municípios, o crime que está sendo cometido é monstruoso. Existe um artigo na Constituição atual, e também em constituições anteriores, que determina que, caso a prefeitura não destine um percentual para o ensino, deverá ser decretada a intervenção. Isso existe na legislação brasileira há quatro 
décadas e nunca houve caso de intervenção em nenhum município brasileiro" (Davies, 2001c, p. 72).

Em síntese, se essas e outras questões estruturais não forem resolvidas, qualquer política de financiamento do ensino médio, mesmo prevendo aumento substancial de recursos, o que não foi o caso da política do governo FHC, será minada na prática, ainda que os discursos e documentos oficiais possam pintar um outro quadro.

\section{Desafios conjunturais}

Após o exame das questões estruturais, passamos a analisar algumas medidas do governo FHC com reflexos no financiamento da educação e, em particular, do ensino médio: a Emenda Constitucional (EC) no 14, o Fundo de Manutenção e Desenvolvimento do Ensino Fundamental e de Valorização do Magistério (Fundef) e o Plano Nacional de Educação (PNE).

Aprovada em setembro de 1996, a EC no 14 é uma iniciativa do governo federal que, entre outras disposições, obriga estados, municípios e Distrito Federal a aplicarem, por dez anos, até 2006 , pelo menos $60 \%$ do percentual constitucional mínimo de $25 \%$ (ou seja, $15 \%$ ) de impostos no ensino fundamental, e cria, no âmbito do Distrito Federal e de cada estado, o Fundef, com vigência obrigatória a partir de lo de janeiro de 1998.

O estabelecimento de tal prioridade do ensino fundamental no âmbito do legislativo (muito mais do que real) segue o diagnóstico de políticas educacionais inspiradas em orientações de organismos representativos do capital internacional, em particular o Banco Mundial. Segundo esse organismo, a crise fiscal dos governos seria resolvida no campo educacional com a priorização do nível de ensino com maior taxa de retorno econômico (supostamente o fundamental) e maior potencial de alívio da pobreza; com a participação da sociedade no financiamento de tais gastos, através de contribuições financeiras ou trabalho voluntário, e com o incentivo à iniciativa privada e às ONGs (organizações não-governamentais) (Torres, 1996).

Tais políticas não prevêem aumento de gastos públicos no setor social, mas apenas sua redistribuição entre esferas de governo ou níveis de ensino, de modo a garantir uma maior eqüidade. O Fundef (regulamentado pela Lei 9.424, de dezembro de 1996), assim como o PNE, sancionado por FHC em janeiro de 2001, são a materialização dessas políticas, pois não trazem recursos novos para o sistema educacional como um todo. Trata-se apenas de uma repartição, entre o governo estadual e seus municípios, de uma parte dos recursos já vinculados à MDE antes da criação do Fundef - 15\% do ICMS, 
FPM, FPE, IPI-exportação e da compensação financeira prevista na Lei Complementar 87/96 — com base no número de matrículas no ensino fundamental regular de cada rede no ano anterior.

Como só tais matrículas representam um potencial de receita, críticos do Fundef argumentam que ele poderia prejudicar os demais níveis e modalidades de ensino, como a educação infantil, a educação de jovens e adultos e o ensino médio, que não oferecem um potencial de receita na redistribuição do Fundef, pois suas matrículas não são levadas em conta nessa redistribuição. Segundo a União Nacional dos Dirigentes Municipais de Educação (Undime), alguns efeitos negativos do Fundef já teriam se manifestado em 1998. Na avaliação divulgada em 16 de março de 1999, teria havido uma diminuição da oferta de vagas na educação infantil por causa do Fundef, o que não se deveu somente à "absorção (...) de crianças de 6 anos no ensino fundamental" (Undime, 1999, p. 3). Também a educação de jovens e adultos teria sofrido com o Fundef, embora num grau menor. A educação especial, cuja oferta vinha crescendo, "tende a estacionar, uma vez que não está devidamente clara a aplicação de recursos do Fundef nessa área" (Undime, op. cit., p. 4). É verdade que, no caso da educação pré-escolar, as matrículas no conjunto das redes municipais e estaduais tiveram um ligeiro crescimento de 1996 (3.248.412) para 2001 (3.593.267), pouco mais de 10\%, percentual que apenas acompanhou o crescimento demográfico no período.

A exemplo de tantas outras políticas sociais no passado e no presente, esta priorização do ensino fundamental pelo governo federal é apenas discursiva, pois a EC 14, ao mesmo tempo que aumentou de 50\% (previstos no Art. 60 do Ato das Disposições Constitucionais Transitórias da CF de 1988) para $60 \%$ dos $25 \%$ dos impostos (ou seja, 15\%) o percentual que municípios, estados e Distrito Federal deveriam aplicar no ensino fundamental, diminuiu de 50\% (previstos no mesmo Art. 60) para nada menos do que o equivalente a $30 \%$ do percentual da sua receita vinculada à $\mathrm{MDE}(18 \%) \mathrm{o}$ que o governo federal deveria aplicar na erradicação do analfabetismo e na manutenção e no desenvolvimento do ensino fundamental.

Como, por esta formulação, o governo federal pode incluir a sua quotaparte (um terço) do salário-educação (que é contribuição social, não imposto) no montante equivalente a $30 \%$, isso significa na prática a permissão legal de aplicação de um percentual bem inferior a 30\% dos 18\% dos impostos federais vinculados à MDE. Considerando-se que o Fundo de Estabilização Fiscal (FEF), sucessor do Fundo Social de Emergência, criado em 1994, desvincula $20 \%$ da receita de impostos federais do ensino, isso significa que o governo federal só vem sendo obrigado a aplicar $14,4 \%$ - $18 \%$ menos $3,6 \%$ (equivalente a $20 \%$ de $18 \%$ ) - dos impostos em MDE e, portanto, $30 \%$ de $14,4 \%$ (equivalente a $4,3 \%$ ) no ensino fundamental e na erradicação do analfabetismo. 


\begin{tabular}{|c|c|c|c|c|c|c|c|}
\hline \multirow[t]{3}{*}{ Ano } & \multicolumn{4}{|c|}{$\begin{array}{l}\text { Valor nacional } \\
\text { mínimo anual (em R\$) }\end{array}$} & \multicolumn{3}{|c|}{$\begin{array}{l}\text { Complementação federal } \\
\text { (em R\$ milhões) }\end{array}$} \\
\hline & \multicolumn{2}{|c|}{$\begin{array}{l}\text { Valor médio } \\
\text { (devido) }\end{array}$} & \multicolumn{2}{|c|}{$\begin{array}{l}\text { Valor fixadopelo MEC } \\
\text { (devido) }\end{array}$} & \multirow[t]{2}{*}{$\begin{array}{l}\text { Total com base } \\
\text { no valor médio }\end{array}$} & \multirow[t]{2}{*}{$\begin{array}{l}\text { Total com base } \\
\text { no valor do MEC }\end{array}$} & \multirow[t]{2}{*}{ Diferença } \\
\hline & $\begin{array}{l}1^{\mathrm{a}} \text { a } 4^{\mathrm{a}} \\
\text { séries }\end{array}$ & $\begin{array}{l}5^{\mathrm{a}} \text { a } 8^{\mathrm{a}} \\
\text { séries e } \\
\text { educ. esp. }\end{array}$ & $\begin{array}{l}1^{\mathrm{a}} \text { a } 4^{\mathrm{a}} \\
\text { séries }\end{array}$ & $\begin{array}{l}5^{\mathrm{a}} \text { a } 8^{\mathrm{a}} \\
\text { séries e } \\
\text { educ. especial }\end{array}$ & & & \\
\hline 1998 & 418,78 & 418,78 & 315 & 315 & $2.060,6$ & 486,7 & $1.573,9$ \\
\hline 1999 & 453,10 & 453,10 & 315 & 315 & $2.590,7$ & 580 & $2.010,7$ \\
\hline 2000 & 511,35 & 536,91 & 333 & 349,65 & 3.128 & 485,5 & $2.642,5$ \\
\hline 2001 & 585,38 & 614,65 & 363 & 381,15 & $3.507,6$ & 391,6 & 3.116 \\
\hline 2002 & 685,66 & 719,95 & 418 & 438,90 & $3.913,5$ & 496,2 & $3.417,3$ \\
\hline total & & & & & $15.200,4$ & $2.378,7$ & $12.760,4$ \\
\hline
\end{tabular}

Fonte: MEC. 2003. Relatório do GT sobre o Fundef

A contradição do governo federal no caso do financiamento do ensino fundamental fica mais gritante quando constatamos a sua complementação para os Fundefs estaduais, que é ilegal, além de irrisória e decrescente em termos reais e percentuais. A exemplo de tantas outras leis, que só são cumpridas quando interessam aos governantes ou a setores do capital ou da burocracia com eles afinados (o Judiciário e os militares, por exemplo), o governo de FHC não cumpriu o § lo do Art. 6o da Lei 9.424, que estabelece o critério de cálculo do valor mínimo nacional do Fundef, referência para a estimativa da complementação federal.

A tabela a seguir, elaborada a partir do relatório do Grupo de Trabalho constituído pelo MEC em 2003 para estudo sobre o valor mínimo nacional por matrícula, mostra a enorme discrepância entre o valor devido legalmente por matrícula, o valor por matrícula fixado pelo $\mathrm{MEC}$, o total devido legalmente se o valor tivesse sido calculado como manda a Lei 9.424, e a diferença entre este total e a complementação efetuada pelo MEC.

Uma vez que o governo federal, em 2003, também não seguiu o cálculo legal do valor mínimo nacional, a complementação federal devida mas não aplicada, de 1998 a 2003, terá alcançado cerca de R\$ 16 bilhões. Como parece provável que a ilegalidade federal continue em 2004, o montante devido não complementado deve superar R\$ 19 bilhões.

Antes de examinar a proposta principal do governo federal de FHC para o financiamento do ensino médio, que foi a de destinar a ele $10 \%$ dos impostos (dos governos estaduais!) não vinculados ao ensino fundamental até 2006, cabe lembrar a dificuldade de estudo dos gastos reais recentes com es- 
te nível de ensino. O maior obstáculo para obter esses dados deve-se ao fato de que tais gastos muitas vezes não são lançados no programa específico do ensino médio.

Segundo Costa (2001, p. 77), os governos estaduais adotariam uma variedade de critérios de alocação de despesas. No Maranhão, por exemplo, as despesas com pessoal da educação são alocadas no programa "Administração", e não nos programas específicos ("educação de 0 a 6 anos", "ensino fundamental", "ensino médio" etc.). Tal procedimento também foi constatado pelo Tribunal de Contas do Distrito Federal (Davies, 2001b, p. 39). Também detectamos este problema nas contas de 2001 do governo estadual do Rio de Janeiro, em que o governo alega ter despendido apenas R\$ 4 milhões com o ensino médio, quando, na verdade, o valor foi muito maior, uma vez que as matrículas neste nível são de 535 mil (MEC, 2001). Isso levou Costa (op. cit., p. 77-78) a afirmar que

\begin{abstract}
"na prática, o total de recursos aplicados no ensino médio é superior ao efetivamente declarado. Isso porque parte dos gastos com ensino médio acaba sendo incorporada ao ensino fundamental, em função de dificuldades operacionais em separá-los. Esse é o caso, por exemplo, de gastos com professores. Em geral, as carreiras não são diferenciadas para os profissionais de $5 \underline{a}$ a 8 a série do ensino fundamental e para os do ensino médio. Muitos deles, efetivamente, lecionam nos dois níveis. Com isso, torna-se complexo fazer a distinção entre os gastos com esses profissionais nos dois níveis de ensino. O mais usual é que praticamente a totalidade desses gastos seja atribuída ao ensino fundamental. O mesmo ocorre em relação a outros itens, especialmente quando se considera que boa parte das escolas que oferecem ensino médio também atua no ensino fundamental, ao menos de $5 \underline{a}$ a $8 \underline{a}$ série. Com isso, pode-se assumir que os gastos declarados em ensino médio nos Estados tendam a estar recorrentemente subestimados" (Costa, 2001, p. 77-78).
\end{abstract}

Na visão do governo de FHC, a subvinculação de $15 \%$ dos impostos para o ensino fundamental e a criação do Fundef pela EC 14 não afetariam o ensino médio, porque os governos estaduais contariam com os $10 \%$ restantes dos $25 \%$ (isso se o percentual das Constituições estaduais for $25 \%$ ), recomendação - não é determinação legal — presente no projeto de PNE, que o MEC enviou ao Congresso em fevereiro de 1998 e que acabou sendo incluída na Lei do PNE, sancionada com vetos (quase que exclusivamente relacionados a aumento de recursos públicos!) por FHC em janeiro de 2001.

A proposta do MEC foi deficiente por não se basear em estudo que comprove serem estes $10 \%$ suficientes para garantir uma expansão qualitativa do ensino médio, como aconteceu com a quantitativa nos anos 90. Em outras palavras, o MEC previu e recomendou tal expansão, porém não definiu a origem dos recursos adicionais necessários, pressupondo apenas que o uso 
"judicioso" das verbas (também chamado de "racionalização dos gastos") iria garantir tal expansão, exercendo no máximo uma função "supletiva" através de projetos, como o de Expansão e Melhoria do Ensino Médio "Escola Jovem" - que prevê US\$ 500 milhões do Banco Interamericano de Desenvolvimento (BID) e US\$ 450 milhões de contrapartida dos governos estaduais, entrando o Tesouro Nacional com US\$ 50 milhões - e o Projeto Alvorada - que previu R \$ 160 milhões em 2000, R\$ 400 milhões em 2001 e R \$ 400 milhões em 2002 aos governos estaduais do Norte e Nordeste que tiveram perdas na repartição dos recursos do Fundef (MEC, 2002).

Vemos, assim, que a contribuição federal para a expansão do ensino médio é insignificante em termos nacionais, ainda que possa não ser desprezível para estados com receita pequena. A contradição entre o discurso e a prática do governo federal fica patente quando observamos a evolução dos seus gastos no ensino médio de 1993 a 1999. Segundo Ribeiro (2001, p. 34), teriam caído de 7,05\% (R \$ 707 milhões) do dispêndio total do MEC, em 1993, para 4,78\% (R \$ 587 milhões), em 1999. Se tomarmos como referência 1995, o primeiro ano do governo FHC, a queda teria sido de 5,56\% (R $\$ 769$ milhões), em 1995, para 4,78\%.

Embora o uso "judicioso" do dinheiro público possa vir a gerar uma receita adicional significativa para o financiamento do ensino médio, é pouco provável que tal uso venha a acontecer no futuro, se levarmos em conta a experiência passada e presente de corrupção e desperdício endêmicos nos governos, mesmo com a lei chamada equivocadamente de "Responsabilidade Fiscal", que, na verdade, é de "Responsabilidade com os Credores", pois seu único objetivo é garantir o pagamento da dívida pública externa e interna mediante a contenção de certos (não todos) gastos estatais, e não o uso mais racional do dinheiro público. Esse dinheiro, por falta de controle social efetivo, continuará sendo abocanhado em proporções crescentes pelas várias frações do capital (sobretudo o financeiro) e pelos vários setores da burocracia estatal (sobretudo os privilegiados, como os da Fazenda, do Judiciário e os militares) com maior poder de barganha e/ou mais estratégicos para a ordem burguesa.

Dois fatos recentes demonstram o significado real desta lei de "responsabilidade com os credores e irresponsabilidade social". Um é a aprovação pelo Senado, em meados de junho de 2002, da elevação do teto da remuneração do Judiciário de cerca de $\mathrm{R} \$ 12$ mil para mais de $\mathrm{R} \$ 17$ mil, que acarretará, até 2005, uma despesa adicional de R \$2,5 bilhões. Outro é o aumento das despesas financeiras (encargos da dívida externa e interna) maior do que o dos dispêndios sociais do governo federal na segunda metade da década de 1990. Segundo Ribeiro (2001, p. 34), elas cresceram de R 71 bilhões, em 1994, para $\mathrm{R} \$ 315$ bilhões (mais de 400\% de aumento), em 1999, enquanto os dispêndios ditos sociais passaram de $\mathrm{R} \$ 41$ bilhões para $\mathrm{R} \$ 114$ bilhões (me- 
nos de $200 \%$ ). Vale lembrar que uma grande parte (talvez a maior) de tais dispêndios sociais não deveria ser contabilizada como tal, pois se refere a pagamento de aposentados e pensionistas, que custearam, pelo menos em parte, suas aposentadorias. Além disso, os gastos do MEC em relação ao PIB caíram de 1,62\%, em 1994, para 1,28\%, em 1999. Em relação à despesa total do governo, a participação do MEC diminuiu de 4,03\%, em 1994, para 2,31\%, em 1998.

Por isso, o mais provável é que a expansão do ensino médio tenha acontecido e venha a acontecer com forte deterioração da qualidade, mediante a ocupação dos espaços ociosos (no horário noturno, sobretudo) das escolas de ensino fundamental e a contratação de profissionais da educação em regime precário, com salários baixos e decrescentes em termos reais. Haveria, assim, a reprodução de algo parecido com o que ocorreu com o aumento da escolaridade compulsória de quatro para oito anos no ensino de primeiro grau e a profissionalização compulsória na Lei 5.692/71, ou seja, aumento de atribuições dos governos subnacionais (estados e municípios) sem os recursos necessários face a tal aumento, uma característica recorrente das políticas federais. As freqüentes notícias sobre falta de professores em várias disciplinas na rede estadual no Rio de Janeiro ao longo da década de 1990 e início da década atual mostram a fragilidade qualitativa da explosão das matrículas do ensino médio.

A fragilidade da recomendação de destinação prioritária dos $10 \%$ para o ensino médio fica mais óbvia ainda quando consideramos o crescimento das matrículas dos vários níveis e modalidades de ensino ministrados pelos governos estaduais na década de 1990, sem o aumento do percentual vinculado à MDE. As matrículas estaduais do ensino médio, por exemplo, aumentaram de 2,472 milhões, em 1991, para 5,301 milhões, em 1998, e 6.962.230, em 2001, enquanto as do ensino fundamental nas redes estaduais cresceram menos, de 16,716 milhões, em 1991, para 18,468 milhões, em 19962. É verdade que, com a implantação do Fundef, em 1998, houve uma transferência maciça de matrículas do ensino fundamental de muitas redes estaduais para redes municipais, resultando na diminuição para 14,917 milhões de matrículas em 2001. Isso, porém, significou ao mesmo tempo perda de recursos dos governos estaduais para os municipais na proporção direta do valor por matrícula no ensino fundamental na unidade federativa.

No caso do ensino médio, além dessa explosão entre 1991 e 2001, se a estimativa da Lei do PNE se confirmar, os governos estaduais terão uma sobrecarga bastante grande durante os dez anos de vigência do PNE, pois a previsão é de que as matrículas alcançariam 10,446 milhões, em 2008. Se a proporção das redes estaduais no conjunto das matrículas do ensino médio continuar a mesma de 1998 (76\%), elas teriam de atender a 7,6 milhões em 2002, 2,3 milhões a mais do que atenderam em 1998. É pouco provável que os $10 \%$ de impostos possam ser comprimidos para garantir tal expansão, so- 
bretudo no contexto de recessão e/ou baixo crescimento econômico, e do fantasma (conveniente para os governantes) da Lei de Responsabilidade Fiscal, que impediria aumento de gastos com pessoal.

Além desta sobrecarga sobre os recursos vinculados à MDE provocada pela expansão do ensino médio nas redes estaduais, é preciso lembrar que alguns governos estaduais (por exemplo, Bahia, Paraná, Rio de Janeiro, São Paulo) possuem instituições de ensino superior que consomem uma proporção considerável dos recursos da educação, reduzindo, portanto, os $10 \%$ teoricamente disponíveis para o ensino médio. As universidades paulistas, por exemplo, dispõem de cerca de $10 \%$ do ICMS, com base na Constituição estadual. Como o percentual mínimo vinculado à MDE pela Constituição estadual é de $30 \%$, isso resulta (considerando-se que o ICMS responde por cerca de $90 \%$ da receita de impostos) em pouco mais de $20 \%$ dos impostos para todos os demais níveis e modalidades de ensino da rede estadual, reduzindo bastante (para pouco mais de $5 \%$ ) o percentual teoricamente disponível para o ensino médio, uma vez que $15 \%$ são vinculados ao ensino fundamental até 2006 pela EC 14.

Também no Rio de Janeiro o ensino médio contaria com bem menos de $10 \%$, pois o governo estadual tem duas universidades estaduais (Uerj e Uenf), que consomem bem mais de $5 \%$ dos impostos. Embora a Constituição Estadual estipule um percentual mínimo de $35 \%$, o governo alega (e o TC aceita a alegação) só ser obrigado a aplicar $25 \%$, com base numa liminar concedida pelo Supremo Tribunal Federal a uma Ação Direta de Inconstitucionalidade movida, em 1993, pelo então governador Brizola. Quando consideramos que as instituições estaduais de ensino superior no Brasil inteiro tiveram um crescimento de $50 \%$ de 1988 a 1998, passando de 190.736 para 274.934 matrículas, e que, se forem manter sua fatia de $12 \%$ no conjunto das matrículas no ensino superior durante a vigência do PNE, tenderão a absorver uma fatia crescente dos recursos vinculados à $\mathrm{MDE}$, os recursos que sobrarão para o ensino médio serão bem inferiores aos $10 \%$ dos impostos.

Conforme aponta Carnoy (1998, p. 247), a propósito do ensino secundário:

\footnotetext{
“Muitas (se não a maioria) das reformas propostas em nome da melhoria da qualidade do ensino e da 'eficiência' dos sistemas educacionais (produzindo mais qualidade pelo mesmo gasto público por aluno) têm como meta prioritária não o melhor desempenho [do] aluno, e sim a redução dos recursos públicos com educação. Como resultado, o desempenho do aluno, em cada nível de ensino, não irá melhorar significativamente em conseqüência destas políticas." (Carnoy, 1998, p. 247)
}

Em síntese, a proposta do uso judicioso dos recursos feita pelo MEC, no governo FHC, ainda que possa gerar um montante razoável para o crescimento do ensino médio, está longe de garantir a expansão quantitativa e 
qualitativa preconizada, mesmo com as orientações oficiais de muito trabalho voluntário, ocupação de espaços ociosos, contribuições de pais de alunos e o emprego de educação a distância (Telecurso 2000, por exemplo). Sem aumento de verbas governamentais para a educação pública, tal expansão poderá ser quantitativa (e mesmo assim não conforme os números previstos) mas com uma qualidade cada vez pior, embora a propaganda oficial possa pintar um quadro cor-de-rosa, com base numa ou outra experiência "positiva" ou "inovadora".

A fragilidade da proposta do MEC fica mais patente quando observamos que a prioridade dos governos não é a política educacional ou social (a não ser quando concebida dentro da perspectiva de congelamento ou redução de gastos públicos ou seu redirecionamento para setores supostamente mais carentes ou maior retorno econômico), mas sim a fiscal/econômica, como exemplifica a Lei de Responsabilidade Fiscal, sempre lembrada pelos governantes quando pressionados a conceder aumentos salariais das categorias menos estratégicas dos servidores públicos (professores, por exemplo), porém deixada de lado quando categorias mais importantes (do ponto de vista dos detentores do poder) reivindicam melhorias salariais, como o Judiciário, quando os detentores do poder precisam de recursos para financiar suas campanhas eleitorais ou quando setores poderosos do capital fazem valer sua força junto aos aparelhos de Estado para obter algum subsídio ou vantagem, tirando recursos que se destinavam à política social/educacional.

Um exemplo deste tipo de assalto do capital ao dinheiro público foi o remanejamento de recursos destinados legalmente à informatização das escolas públicas para cobrir supostos prejuízos das empresas de telecomunicações Telemar, Telefonica e Brasil Telecom. Segundo Elio Gaspari (2002), o governo federal já teria enviado ao Congresso um projeto de lei reduzindo os recursos do Fundo de Universalização dos Serviços de Telecomunicações (Fust), formado por $1 \%$ do faturamento dessas empresas, de R $\$ 480$ milhões para R \$ 119 milhões, para a informatização das escolas públicas, e de R \$ 327 milhões para $\mathrm{R} \$ 60,7$ milhões, para a saúde. Tudo isso, e mais uma infinidade de outros exemplos veiculados pelos meios de comunicação nos últimos anos, só confirma a tendência maior do Estado capitalista brasileiro, que é a de privilegiar a política fiscal/econômica (ou seja, a reprodução do capital) e deixar em segundo plano a política social/educacional, a qual, embora contribua também (não apenas) para a reprodução do capital, o faz de modo indireto e a longo prazo, ao contrário da política fiscal/econômica, cujos efeitos são imediatos, condizentes, pois, com o imediatismo do capital, que, se hoje está aqui, amanhã poderá se deslocar para outros países e regiões menos "inseguros" e/ou com maior taxa de retorno. 


\section{O financiamento da educação no governo Lula: o "ajuste fiscal" continua?}

Até dezembro de 2003, os elementos de que dispomos sobre o governo Lula apontam no sentido da continuidade do "ajuste fiscal" perpetrado por FHC às custas dos trabalhadores, sobretudo dos trabalhadores organizados. A começar pela concessão da esmola a título de aumento salarial aos servidores federais muito aquém da inflação oficial de 2003, sem falar nas perdas salariais acumuladas durante o seu governo, apesar do crescimento da receita tributária federal nos últimos anos e também nos primeiros meses de 2003. Esta medida concreta já estaria em contradição com o programa do governo Lula para a educação (PT, 2003) no item "Valorização Profissional", que promete a "irredutibilidade dos salários, assegurada a reposição anual de perdas, a integralidade dos proventos de aposentadoria e de pensões".

Em segundo lugar, este documento, que entra em muitos detalhes (não financeiros!) sobre níveis e modalidades de ensino nos quais o governo federal não atua prioritariamente, pelo menos do ponto de vista constitucional, como a educação infantil, ensino fundamental, educação especial, ensino médio, é excessivamente lacônico ao tratar do financiamento (que só ocupa cerca de $2 \%$ do documento!) para prometer apenas reexaminar os vetos apostos por FHC ao PNE para que "através do esforço conjunto da União, Estados, Distrito Federal e municípios, o percentual de gastos públicos em educação em relação ao PIB sejam elevados para o mínimo de 7\% no período de dez anos" (PT, 2003).

Numa análise dos programas para a Educação Superior dos candidatos à presidência da República, em agosto de 2002, o Grupo de Trabalho (GT) de Política Educacional da Associação Nacional dos Docentes do Ensino Superior (Andes) já fazia ressalvas a essa proposta por defender o "reexame dos vetos de FHC ao PNE, mas não assumir nenhum compromisso com seu não-acatamento", legitimando o PNE do governo FHC “ao se limitar apenas a rever os vetos (...) [e diferindo] da proposta da Andes-SN e do PNE da sociedade brasileira, ao não se contrapor à Lei de Responsabilidade Fiscal e ao Fundo de Estabilização Fiscal, que retira verba da educação" (Andes, 2002). Assim, o programa não pretende tomar como referência a meta de $10 \%$ do Produto Interno Bruto (PIB) fixada pelo PNE, elaborado em novembro de 1997 pelas entidades de trabalhadores da educação que participaram do II Congresso Nacional de Educação (Coned), também chamado de "PNE da sociedade brasileira".

Este percentual mínimo de 7\%, no entanto, parece estar em contradição com a carta-compromisso do Partido dos Trabalhadores (PT), que prometeu usar como parâmetro o PNE elaborado pela sociedade (10\% do PIB), segundo a edição especial do Jornal Mural da Confederação Nacional dos Trabalhadores em Educação (CNTE), de fevereiro de 2003. Não tive acesso a 
esta carta-compromisso, mas é possível que tal contradição se deva ao fato de o programa de governo ter sido elaborado, se não totalmente, pelo menos em grande parte, pela ONG de Lula, o Instituto de Cidadania, uma instância inexistente na estrutura partidária. De qualquer maneira, qualquer que seja o percentual, $7 \%$ ou $10 \%$, como o prazo para a aplicação é de dez anos, a partir da aprovação da Lei do PNE (janeiro de 2001), e como a lei não prevê aumento dos percentuais ao longo desse prazo, isso significa que o conjunto dos governos (sim, pois o percentual vale para as três esferas de governo, e não apenas para o governo federal) só seria obrigado a aplicar este percentual em 2011. Como o governo Lula termina em 2006 (no caso de não ser reeleito), ele não se verá obrigado a cumprir o que está previsto na lei.

Além disso, conforme já salientamos em artigo anterior sobre o Plano Nacional de Educação (Davies, 2001d), como o percentual vale para o conjunto dos governos federal, estaduais, municipais e do Distrito Federal, e não há nenhuma definição sobre o percentual que cabe a cada governo, não se poderá cobrar responsabilidade de nenhuma esfera de governo, uma vez que ela é de todos, conjuntamente. Outro problema é que a receita dos governos não é constituída de PIB, mas sim de impostos, taxas etc., sendo o PIB (pelo menos o registrado na contabilidade oficial) um bom indicador para aferir uma série de gastos, mas não para cobrar responsabilidade de governos.

Um terceiro elemento negativo para o financiamento da educação é a proposta de Emenda Constitucional 41 (reforma tributária), encaminhada em abril de 2003 ao Congresso Nacional, prevendo a prorrogação do Fundo de Estabilização Fiscal (FEF) até 2007. Por esta proposta, o Art. 76 do Ato das Disposições Constitucionais Transitórias passaria a ter a seguinte redação: “É desvinculado de órgão, fundo ou despesa, no período de 2003 a 2007, 20\% da arrecadação da União de impostos, contribuições sociais e de intervenção no domínio econômico, já instituídos ou que vierem a ser criados no referido período, seus adicionais e respectivos acréscimos legais". Como é sabido, o FEF - desde a sua criação, pela Emenda Constitucional de Revisão 1, em 1994, com o nome de Fundo Social de Emergência, e prorrogações posteriores (pelas Emendas Constitucionais 10, de 1996, 17, de 1997, e 27, de 2000) - trouxe imensos prejuízos ao financiamento da educação ao desvincular $20 \%$ da receita de impostos e contribuições. Com isso, a obrigação constitucional do governo federal de aplicação em manutenção e desenvolvimento do ensino caiu de $18 \%$ para $14,4 \%$, pois $20 \%$ dos $18 \%$ significam 3,6\%, retirados da educação em âmbito federal.

Para se ter uma idéia do prejuízo provocado por tal esperteza contábil, essa desvinculação da receita da União (conhecida como DRU desde a Emenda Constitucional 27, de março de 2000) desvinculou R \$ 8,3 bilhões da receita de impostos federais de janeiro a abril de 2003, o que totalizou R $\$ 40,2$ bilhões no período (dados obtidos em www.stn.fazenda.gov.br, site da Se- 
cretaria do Tesouro Nacional). Se não houvesse essa desvinculação, a base de cálculo dos 18\% seria de mais de R \$ 21 bilhões (após as transferências constitucionais de R \$ 18,9 bilhões para estados e municípios), e não de R\$ 12,9 bilhões, resultado da subtração dos R \$ 8,3 bilhões. Projetando-se os R\$ 8,3 bilhões desvinculados para o ano inteiro, isso resultará em cerca de $\mathrm{R} \$$ 25 bilhões $(8,3 \times 3)$ a menos na base de cálculo dos $18 \%$. Em outras palavras, a educação em âmbito federal perderia R \$ 4,5 bilhões (18\% de R \$ 25 bilhões) só em 2003. Este desfalque para a educação será ainda maior porque a DRU irá também desvincular $20 \%$ da contribuição social do salárioeducação, cuja receita de janeiro a abril de 2003 foi de cerca de R\$ 1,2 bilhão, que, projetada para o ano inteiro, totalizará R \$3,6 bilhões, 20\% dos quais resultam em $\mathrm{R} \$ 720$ milhões. Em suma, o prejuízo causado pela PEC 41 à educação só em 2003 será em torno de R\$ 5,2 bilhões (R \$ 4,5 bilhões + $\mathrm{R} \$ 720$ milhões).

O que é mais grave no FEF é que foi criado com o discurso de que se destinaria a custear ações de saúde e educação, porém tem sido muito mais usado para financiar outros setores. Segundo o Relatório e Parecer Prévio do Tribunal de Contas da União (TCU) sobre as contas do governo federal em 1999, os recursos do FEF

“por funções em 1999 foram aplicados em Defesa Nacional e Segurança Pública (R \$ 7,7 bilhões), Assistência e Previdência ( $\mathrm{R}$ \$ 3,8 bilhões), Judiciária (R \$ 3,1 bilhões), Saúde e Saneamento (R \$ 2,8 bilhões), Administração e Planejamento (R \$ 2,6 bilhões), Educação e Cultura (R \$ 2,3 bilhões), Agricultura (R \$ 1,2 bilhão) e demais (R\$ 1,5 bilhão)" (Brasil, TCU, 2000, p. 27).

\section{Fundeb: a nova panacéia?}

Antes de analisar a proposta petista de se criar o Fundo de Manutenção e Desenvolvimento da Educação Básica Pública e de Valorização dos Profissionais da Educação (Fundeb), que supostamente corrigiria os males do Fundef, cabe ressaltar dois fatos que fragilizam a proposta ou pelo menos sua intenção declarada. Um é que nem o valor mínimo anual por matrícula previsto no Fundef, criado pela Emenda Constitucional 14 e regulamentado pela Lei 9.424, está sendo cumprido pelo atual governo, embora este descumprimento tenha sido veementemente denunciado pelo PT durante o governo de FHC. De acordo com a CNTE (2003),

“o governo federal determinou valores mínimos para o Fundef inferiores ao que determina a lei. Segundo especialistas, a correta interpretação do Art. 60 da Lei 9424/96 (...) resultaria em um repasse de $\mathrm{R} \$ 733,80$, para alunos de 1a a 4a série, 
e de $\mathrm{R} \$ 770,50$, para os de $5 \underline{a}$ a 8 a série (...). Mas o decreto 4.580, do presidente Luís Inácio Lula da Silva, redigido a partir de recomendação do Ministério da Fazenda, (...) determinou que os valores mínimos para o Fundef este ano sejam de R\$ 446,00, para estudantes de la a 4a série, e R\$468,30, para os de 5a a $8 \underline{a}$ série." (CNTE Notícias, fev. 2003)

Por conta dessa discrepância entre os valores mínimos fixados pelo governo e os devidos de acordo com a lei, o governo federal deixará de complementar em 2003 com mais de R\$ 3 bilhões aos Fundefs estaduais que não conseguirem alcançar o valor mínimo por matrícula, ampliando, assim, a dívida acumulada de mais de R\$ 12 bilhões de 1998 a 2002 de complementação federal legalmente devida aos Fundefs estaduais.

Outro fato é que o aumento e melhoria dos gastos federais em educação não dependem da criação do Fundeb, que, por ser uma proposta de emenda constitucional, depende da aprovação de três quintos dos deputados federais e senadores. Basta vontade política, o que o atual governo não tem demonstrado, optando pelo "ajuste fiscal", através de propostas como as reformas previdenciária e tributária, para gerar receita adicional para pagar sobretudo os juros (não necessariamente o principal) da dívida interna e externa, em suma, para remunerar o capital financeiro, também beneficiado com uma das mais altas taxas de juros do mundo em termos reais, embora decrescente nos últimos meses de 2003. De qualquer maneira, vale lembrar que o Fundeb terá muitas dificuldades de aprovação porque representará perdas de receitas para os governos estaduais, que mobilizarão seus deputados e senadores para impedir sua aprovação, ou pelo menos desfigurá-lo de modo a diminuir tais perdas.

Com relação ao Fundeb propriamente dito, cabe lembrar que não é uma proposta nova, pois foi apresentada por deputados do PT, através da PEC 112, em setembro de 1999 (Brasil, Câmara dos Deputados, 1999), para corrigir muitos dos problemas do Fundef. As diferenças básicas do Fundeb em relação ao Fundef são: 1) 25\% de todos os impostos dos estados, Distrito Federal e municípios constituem o Fundeb, e não apenas 15\% de alguns impostos, como no caso do Fundef; 2) todas as matrículas iniciais da educação básica (educação infantil, ensino fundamental, ensino médio), assim como toda a população de 0 a 17 anos e a de jovens e adultos que não teve escola na idade própria são consideradas na distribuição dos recursos, e não apenas as do ensino fundamental regular, como no Fundef; 3) o governo federal faz uma suplementação para garantir um padrão mínimo de qualidade nos governos estaduais, municipais e do Distrito Federal cujos 25\% dos impostos não sejam suficientes para os custos-aluno-qualidade (diferenciados segundo o nível e modalidade de ensino), a serem definidos em lei complementar; 4) 80\% do Fundeb se destinam à valorização de todos os profissio- 
nais da educação básica, ao contrário do Fundef, que prevê, pela Lei 9.424, pelo menos $60 \%$ desses $15 \%$ de alguns impostos para os profissionais do magistério no ensino fundamental; 5) instituição de Conselhos Gestores com representação do poder Executivo estadual e municipal e da sociedade civil, a serem definidos em lei complementar.

Além disso, a PEC 112 obrigaria o governo federal a gastar $20 \%$ dos impostos em MDE (ao contrário dos atuais 18\%) e os governos estaduais e municipais, no prazo de cinco anos, a não usarem os $25 \%$ dos impostos para financiar suas instituições de ensino superior, reservando-os apenas para a educação básica.

A proposta é um avanço em relação ao Fundef porque pensa a educação básica e os profissionais da educação como um todo e se baseia no critério de custos-aluno-qualidade de acordo com o nível e modalidade de ensino. Outro ponto positivo é pretender fazer um nivelamento por cima (pelo menos em tese, com a idéia de custos-aluno-qualidade), e não por baixo, como tem feito o governo federal na implementação do Fundef.

Entretanto, a proposta apresenta alguns elementos insuficientes e pouco claros, talvez sanados ou atenuados pela futura lei complementar tantas vezes mencionada na PEC 112, mas que não foram esclarecidos na proposta. Um elemento pouco claro é a operacionalização do Fundo, que, às vezes, parece reunir impostos apenas de um governo e, às vezes, do conjunto do governo estadual e prefeituras de cada Unidade Federativa. A redação proposta para o $\S 10$ o do Art. 211 da CF, por exemplo, determina que $80 \%$ dos fundos sejam aplicados na valorização dos profissionais da educação. Ora, como tais profissionais são vinculados juridicamente a governos específicos (estaduais ou municipais), não a Fundebs, parece razoável supor que haverá tantos Fundebs quanto governos estaduais e municipais, para a implementação do cálculo de 80 \% para a "valorização", termo vago e inepto, pois o correto seria "remuneração", algo mais definível. Parece, pois, razoável supor que toda prefeitura e governo estadual teria o seu Fundeb, além do Distrito Federal.

Isso é confirmado por João Monlevade (1999), aparentemente um dos inspiradores/formuladores do Fundeb, que, no texto "Por que Fundeb e não mais Fundef", faz referência a conselhos gestores de fundos estaduais e municipais. Em outros parágrafos, no entanto, dá a entender que o Fundeb não opera isoladamente em cada ente político (município, estado, União), pois pretende promover uma redistribuição dos recursos vinculados à MDE entre diferentes esferas de governo. A redação proposta para o § 6o do Art. 211 da $\mathrm{CF}$, por exemplo, sugere isso vagamente ao afirmar que

“A distribuição de responsabilidades e recursos financeiros em educação básica entre a União, os Estados e Municípios tomará por base a população de zero a 17 
anos de idade, mais a população de jovens e adultos que não teve educação na idade própria, as matrículas iniciais, a permanência do aluno na escola e as receitas de impostos, nos termos a serem definidos em lei complementar e nos Planos Municipais, Estaduais e Nacional de Educação." (Brasil, Câmara dos Deputados, 1999, Proposta de Emenda Constitucional 112 (Fundeb), grifos nossos)

Em outras palavras, o Fundeb redistribuiria os 25\% entre diferentes esferas de governo com base nos parâmetros citados acima, porém não fica claro, afora a suplementação federal, se essa distribuição é do estado para os municípios ou vice-versa, ou de um município para outro.

Já a redação proposta para os $\S \S 7$ o e 11 do Art. 211 da CF dá a entender que o Fundeb irá operar em âmbito estadual, porém não esclarece se os $25 \%$ dos impostos do governo estadual e de todas as prefeituras serão reunidos no Fundeb e distribuídos a cada governo de acordo com os custos-aluno-qualidade diferenciados (semelhante ao mecanismo do Fundef de distribuição de $15 \%$ de alguns impostos estaduais e municipais de acordo com o número de matrículas no ensino fundamental regular). A operacionalização do Fundeb apenas em âmbito estadual (não municipal) fica subentendida na redação proposta para o $\S 7$ o , que prevê a suplementação federal apenas aos estados e Distrito Federal, não mencionando os municípios.

Este caráter estadual é reforçado pelo $§ 11$, que prevê a existência de Conselhos Gestores aparentemente estaduais, pois formados por representação do poder Executivo estadual e municipal e da sociedade civil, não havendo menção a Conselhos municipais. Se os Fundebs operarem em âmbito estadual (e não municipal) e forem geridos por um Conselho de abrangência estadual, não fica claro o papel a ser desempenhado pelas Secretarias Estaduais e Municipais de Educação, que se tornarão dispensáveis. A dúvida que fica é se estes Conselhos terão estrutura e agilidade para gerir tais recursos. Se forem de âmbito estadual e constituídos por $25 \%$ de todos os impostos estaduais e municipais e distribuídos ao governo estadual e aos municipais de acordo com os custos-aluno-qualidade relativos às matrículas reais e potenciais listadas na redação proposta para o $\S 6$ o do art. 211 , recebendo a suplementação federal apenas quando os valores disponíveis em âmbito estadual não forem suficientes para garantir tais custos-aluno-qualidade, não resolverão a desigualdade tributária entre os diferentes governos. Isso enfraqueceria uma das pretensões da PEC 112, que é a “organização do sistema de ensino de forma solidária entre a União, os Estados, o Distrito Federal e os Municípios" (Proposta de Emenda Constitucional 112, grifo nosso).

Ora, da mesma forma que a complementação federal para o Fundef, a suplementação federal prevista na PEC 112 apenas atenua as desigualdades, não garantindo a mesma disponibilidade de recursos por aluno em todas as redes estaduais e municipais brasileiras. A receita do salário-educação (es- 
tranhamente não incluído na PEC 112) em 2002 exemplifica essa desigualdade entre os governos. Dos R \$ 3,5 bilhões arrecadados nacionalmente em 2002, um terço ficou com o governo federal (que os redistribui através de programas, como o do livro didático e da merenda escolar), sendo os $2 / 3$ restantes devolvidos aos Estados onde foram recolhidos. Cerca de 1/3 (mais de R\$ 1 bilhão) foi devolvido ao governo estadual de São Paulo, e 1/3, aos demais 25 governos estaduais. Pela Lei Federal 9.766, de 1998, os governos estaduais deveriam regulamentar a divisão dessa receita com os municípios, porém muitos (como o do Rio de Janeiro, com receita anual em torno de R\$ 300 milhões) não o fizeram até 2003 (5 anos depois!), o que significa que vêm ficando com a totalidade do salário-educação.

Outra fragilidade do Fundeb é considerar, como critério de distribuição de recursos, a população de 0 a 17 anos e a de jovens e adultos que não teve escola na idade própria. Só faz sentido essa distribuição com base nos alunos atendidos, não na população potencialmente escolarizável, pois ela muitas vezes não recebe a devida oferta de escola pelos governos.

Um grande ponto fraco, no entanto, não está no seu conteúdo explícito, mas na sua suposição ingênua de que os valores disponíveis para o custo-aluno-qualidade sejam realmente aplicados pelos governantes para beneficiar a qualidade do ensino. Ora, os nossos estudos sobre gastos em educação de governos (estadual e municipais) fluminenses demonstram a não-aplicação de montantes astronômicos, com a conivência da imensa maioria dos "representantes" do povo (deputados e vereadores) e dos Tribunais de Contas (Davies, 2000). A não-aplicação de bilhões de reais devidos em educação também foi constatada em São Paulo pelo menos de 1995 a 1999, tendo inclusive suscitado uma ação civil pública do Ministério Público Estadual de São Paulo em fevereiro de 2001 (São Paulo, 1999).

Como reconheceu o senador João Calmon, em depoimento prestado à Comissão Parlamentar de Inquérito constituída em 1988 para apurar a aplicação das verbas da educação, este problema é obviamente nacional e não se restringe ao Rio de Janeiro e São Paulo. Por isso, a proposta do Fundeb, se aprovada em Emenda Constitucional, pode, na prática, ser subvertida pelas práticas concretas dos governantes e pela cumplicidade do Legislativo e do Judiciário.

\section{Notas}

1 Professor da Faculdade de Educação da Universidade Federal Fluminense (UFF), Niterói, RJ, Doutor em Sociologia pela Universidade de São Paulo (USP). e-mail: <ndavies@ uol.com.br>.

2 Os dados de 1991 e 1996 foram extraídos do Plano do MEC (MEC, 1998); os de 1998, da Lei 10.172 (Brasil, 2001), e os de 2001, do Censo Escolar de 2001 (MEC, 2001). 
ANDES/GTPE (Associação Nacional dos Docentes das Instituições de Ensino Superior/Grupo de Trabalho de Política Educacional). 2002. Análise comparativa dos programas para a Educação Superior dos candidatos à presidência da República. Brasília: Andes.

BRASIL. 1986. Constituições do Brasil (de 1824, 1891, 1934, 1937, 1946 e 1967 e suas alterações). Brasília: Senado Federal, Subsecretaria de Edições Técnicas. 1988. Constituição da República Federativa do Brasil. Disponível em: <www.se nado.gov.br>. Acesso em: 12 maio 2003. 1996a. Emenda Constitucional 14, de 12 de setembro de 1996. Disponível em: $<$ www. planalto.gov.br>. Acesso em: 15 jan. 1997.

1996b. Lei 9.394, de 20 de dezembro de 1996. Estabelece as Diretrizes e Bases da Educação Nacional. Disponível em: $<$ www.planalto.gov.br>. Acesso em: 15 jan.1997.

1996c. Lei 9.424, de 24 de dezembro de 1996. Dispõe sobre o Fundo de Manutenção e Desenvolvimento do Ensino Fundamental e de Valorização do Magistério e dá outras providências. Disponível em: <www.planalto.gov.br>. Acesso em: 15 jan.1997.

. Congresso Nacional. Câmara dos Deputados. 1999. Proposta de Emenda Constitucional 112 (Fundeb), de 2/09/ 1999. Brasília.

. TCU (Tribunal de Contas da União). 2000. Relatório e parecer prévio sobre as contas do governo da República. Exercício de 1999. Brasília: TCU.

2001. Lei 10.172, de 9 de janeiro de 2001. Estabelece o Plano Nacional de Educação. Disponível em: <www.pla nalto.gov.br>. Acesso em: 15 fev. 2001. 2003. Proposta de Emenda Constitucional de Reforma Tributária. Brasília. Disponível em: <www.planalto.gov.br $>$. Acesso em: 25 maio 2003.

CALLEGARI, Cesar. 1997. As verbas da educação: a luta contra a sonegação de recursos do ensino público no Estado de
São Paulo. São Paulo: Editora Entrelinhas.

1999. CPI da educação: uma ampla exposição de motivos. São Paulo: Assembléia Legislativa.

CAMPOS, Maria Machado Malta. 1985. Escola e participação popular. In: Educação na América Latina: os modelos teóricos e a realidade social (Madeira, Felícia Recher e Melo, Guiomar Namo de, orgs.), pp. 81-114, São Paulo: Cortez/Autores Associados.

CARNOY, Martins. 1998. A transformação do papel da educação secundária em países altamente desenvolvidos e na América Latina: da elite à massa para a escolarização universal. In: CONSED. Coletânea Seminário Internacional Políticas Públicas do Ensino Médio, 29 e 30 de agosto de 1996. São Paulo: CONSED.

CNTE (Confederação Nacional dos Trabalhadores em Educação). 2003. Jornal Mural. Brasília, fev. 2003. (Edição especial).

COSTA, Vera Lúcia Cabral. 2001. Financiamento e gasto com o ensino médio no Brasil. Em Aberto, 18(74):72-80.

DAVIES, Nicholas. 1997. Os recursos financeiros na LDB. Universidade e Sociedade, 14:56-63.

1998. Política fiscal golpeia política educacional. Universidade e Sociedade, 15:60-64.

. 1999a. O estatal, o público e o privado em educação: tensões e ambigüidades. Tese de doutorado em Sociologia, São Paulo: Departamento de Sociologia, Universidade de São Paulo.

. 1999b. Tribunal de Contas: faz as contas ou "faz de conta" na avaliação dos gastos governamentais em educação. Revista Brasileira de Estudos Pedagógicos, 80(194):19-27.

2000. Verbas da educação: o legal $x o$ real. Niterói, RJ: Editora da Universidade Federal Fluminense (Eduff). 2001a. Educação do município do Rio de Janeiro perdeu mais de R 1 bilhão em 1998 e 1999. Movimento, 3:75-88. . 2001b. Tribunais de contas e educação: 
quem controla o fiscalizador dos recursos? Brasília: Editora Plano.

2001c. O Fundef e as verbas da educação. São Paulo: Xamã.

. 2001d. Plano Nacional de Educação: muito discurso, nenhum recurso. Universidade e Sociedade, 25:29-39.

2002. O financiamento público às escolas privadas. Universidade e Sociedade, 27:74-91.

. 2003. O financiamento da educação no governo Lula: o "ajuste fiscal" continua. Universidade e Sociedade, 30:69-75.

FÓRUM NACIONAL EM DEFESA DA ESCOLA PÚBLICA. 1997. Plano Nacional de Educação. Proposta da Sociedade Brasileira. Plano elaborado pelas entidades participantes do II Coned (Congresso Nacional de Educação), realizado em Belo Horizonte, de 6 a 9 de novembro de 1997.

2002. Caderno de subsídios ao 4o Congresso Nacional de Educação (Coned). São Paulo, 23 a 26 de abril de 2002.

GASPARI, Elio. 2002. O dinheiro das escolas vai para a privataria. $O$ Globo, 30 jun., p. 15.

GOMES, Cândido Alberto. 1994. Os caminhos e descaminhos dos recursos financeiros em educação. Revista Brasileira de Estudos Pedagógicos, Brasília, (75)179/ 180/181:9-32.

MACHADO Jr., J. Teixeira e REIS, Heraldo da Costa. 1997. A Lei 4.320 comentada. 28a ed. Rio de Janeiro: Instituto Brasileiro de Administração Municipal.

MEC (Ministério da Educação). 1997. Parecer no CP 26/97, de 2 de dezembro de 1997. Brasília: Conselho Nacional de Educação. Conselho Pleno. 1998. Plano Nacional de Educação. Brasília: INEP.

1999. Balanço do Primeiro Ano do Fundef. Disponível em: <www.mec.gov. br>. Acesso em: 13 mar. 1999

.000. Balanço do Fundef em 1998-2000. Disponível em: <www.mec.gov.br>. Acesso em: 6 nov. 2000.

.2001. Censo escolar de 2001. Brasília:
INEP. Disponível em: <www.inep. gov. br>. Acesso em: 30 maio 2002.

2002. Projetos "Escola Jovem" e "Alvorada". Disponível em: <www.mec.gov .br>. Acesso em: 23 jun. 2002.

2003. Relatório do GT sobre o Fundef. Brasília. Disponível em: <www.mec. gov.br>. Acesso em: 20 ago. 2003.

MELCHIOR, José Carlos de Araújo. 1997. Mudanças no financiamento da educação no Brasil. Campinas: Editora Autores Associados.

1991. Financiamento da educação e gestão democrática dos recursos financeiros públicos em educação. Revista Brasileira de Estudos Pedagógicos, 72(172): 262-290.

1988. O financiamento da educação e a nova LDB. Educação Municipal, 1(3):1833.

1987. O financiamento da educação no Brasil. São Paulo: EPU.

MONLEVADE, João. 1999. Por que Fundeb e não mais Fundef? (mimeo)

MINISTÉRIO DA FAZENDA. Secretaria do Tesouro Nacional. 2003. Receita e despesa de janeiro a abril de 2003. Disponível em: <www.stn.fazenda.gov.br>. Acesso em: 31 maio 2003.

NEGRI, Barjas. 1997. Financiamento da educação no Brasil. Brasília: INEP.

O GLOBO. 1997. Estados querem que união compense perdas do ICMS. O Globo, Rio de Janeiro, 21 ago. Primeiro Caderno. Disponível em: <http://oglobo.globo. com/jornal/>. Acesso em: 26 jan. 2004.

PT (Partido dos Trabalhadores). 2003. Uma escola do tamanho do Brasil. Cadernos Temáticos do Programa de governo. Disponível em: <www.pt.org.br>. Acesso em: 15 mar. 2003.

RIBEIRO, José Aparecido Carlos. 2001. Financiamento e gestão do Ministério da Educação nos anos 90. Em Aberto, 18 (74):33-42.

RIO GRANDE DO SUL. TCE (Tribunal de Contas do Estado). 1998. O papel dos tribunais de contas na reforma educacional. In: Anais do I Seminário Compa- 
rativo de Procedimentos de Fiscalização. São Paulo: Tribunal de Contas do Estado de São Paulo. Disponível em: <www. tce.rs.gov.br/Estudos/pdf/reforma_ensino.pdf $>$. Acesso em: 23 jan. 2004.

SÃO PAULO. Assembléia Legislativa.1999. CPI Verbas da Educação. Disponível em: $<$ http://www.al.sp.gov.br/indexcpi.htm>. Acesso em: 26 jan. 2004.

TORRES, Rosa Maria. 1996. Melhorar a qualidade da educação básica? As estratégias do Banco Mundial. In: O Banco Mundial e as politicas educacionais (Tommasi, Livia et al.), pp.125-193, São Paulo: Cortez.

UNDIME (União Nacional dos Dirigentes Municipais de Educação). 1999. O Fundef na avaliação da Undime. Brasília: Undime.

VELLOSO, Jacques. 1988a. A nova Lei de Diretrizes e Bases da Educação e o financiamento do ensino: pontos de partida. Educação \& Sociedade, X(30):5-42.

1988b. Investimento público em educação: quanto e onde? Ciência e Cultura, 40(4):359-365.

1991. A caminho do ensino médio obrigatório e gratuito: recursos e políticas. In: Ensino médio como educação básica, pp. 7-70. São Paulo: Cortez, Brasília: MEC/Secretaria Nacional de Educação Básica.

WAHRHAFTIG, Ramiro. 1999. O Consed e o ensino médio. In: COSTA, Vera Lúcia Cabral (org.). Descentralização da educação: novas formas de coordenação e financiamento, pp. 203-215, São Paulo: Edições Fundap/Cortez Editora. 